\title{
REPERCUSSÕES DO NOVO CÓDIGO DE PROCESSO CIVIL NO DIREITO PROCESSUASL PENAL: FUNDAMENTAÇÃO DAS DECISÕES
}

\author{
Andreza Cristina Baggio * \\ André Luis Pontarolli**
}

\section{RESUMO}

O presente artigo se propõe, mediante metodologia de revisão bibliográfica, ao estudo parcial das repercussões do novo Código de Processo Civil no Direito Processual Penal. A análise proposta recai (problema) sobre a viabilidade hipotética de aplicação ao Processo Penal das novas disposições processuais civis que reforçam o princípio constitucional da fundamentação decisória. A hipótese desenvolvida parte da afirmação de que a as novas normas que dispõem sobre a fundamentação podem ser aplicadas no âmbito processual penal, vez que ampliativas de garantia fundamental. O desenvolvimento da hipótese se prende aos fundamentos constitucionais comuns a ambos os sistemas processuais.

Palavras-chave: Processo Civil; Processo Penal; Fundamentação das decisões; Novo CPC; Constituição

\section{REPERCUSSIONS OF THE NEW CIVIL PROCEDURAL CODE IN CRIMINAL PROCEDURAL LAW: REASONING OF JUDICIAL DECISIONS}

\begin{abstract}
This article proposes, through bibliographic review methodology, to study the repercussions of the new Code of Civil Procedure in Criminal Procedural Law. The proposed analysis is based (problem) on the hypothetical applying to the criminal procedure new provisions which reinforce the constitutional principle of the justification of decisions. The hypothesis developed is part of the assertion that the new rules that have on the basis of decision can be applied in the criminal procedural, instead of extending the fundamental guarantee. The development of the hypothesis is based on the constitutional foundations common to both procedural systems.
\end{abstract}

Keywords: Civil Procedure; Criminal Procedure; Reasoning; New CPC; Constitution

\section{INTRODUÇÃO}

\footnotetext{
* Professora Universitária do Centro Universitário Internacional (PPGD-UNINTER-PR); Doutora em Direito Econômico e Socioambiental pela Pontifícia Universidade Católica do Paraná; baggio.andreza@gmail.com

** Mestrando em Direito (PPGD-UNINTER); Pesquisador da Linha de Pesquisa Jurisdição e Processo na Contemporaneidade (PPGD-UNINTER); Professor Universitário (UNIOPET); andre_pontarolli@hotmail.com
} 
A partir da vigência do novo Código de Processo Civil, a doutrina passou a se debruçar, entre outras questões, sobre a possibilidade de aplicação subsidiária das novas normas processuais civis ao Processo Penal.

Tal perspectiva analítica é extremamente relevante, vez que capaz de evidenciar os caminhos conectivos potenciais entre o Processo Penal e o Processo Civil de viés constitucional, voltado à efetivação de direitos fundamentais. Reside aí, portanto, problema dogmático de significativa importância - e amplitude - a ser investigado.

Dentro desta problemática nitidamente abrangente, surgem outras mais restritas, a exemplo do problema que norteia a presente pesquisa, qual seja: saber se é viável a aplicação, ao Processo Penal, das novas normas processuais civis que dispõem especificamente sobre a fundamentação das decisões judiciais.

Vale ressaltar que outros pontos de conexão entre Processo civil e Processo Penal poderiam ser problematizados, mas a questão da fundamentação decisória - notadamente quando se passa a refletir sobre uma nova "teoria da decisão" - parece se destacar, revelandose, assim, a justificativa do presente trabalho.

Isto porque não se mostra minimamente razoável pensar a jurisdição - pelo aspecto decisório - de forma dividida: de um lado a processual civil com requisitos decisórios mais amplos; de outro lado a processual penal com requisitos decisórios menos amplos.

Enfim, sendo a fundamentação "exigência" constitucional à jurisdição, é de se acreditar - e aqui já se inicia a construção da hipótese a ser pesquisada - que a regulamentação infraconstitucional, no caso ampliativa do preceito fundamental (exigência de fundamentação das decisões) deve ser aplicada à jurisdição como um todo (processual civil e processual penal), podendo-se invocar, inclusive, o princípio da universalidade jurisdicional.

Assim, considerando que os dispositivos do novo Código de Processo Civil ampliaram a extensão conceitual do princípio da fundamentação das decisões judiciais, na busca de efetivação de um processo justo, apresenta-se como hipótese, aparentemente viável - a ser avaliada no curso do trabalho, através dos métodos de análise normativa e revisão bibliográfica - a possibilidade de aplicação de tais regras ao Direito Processual Penal.

\section{NOVO CÓDIGO DE PROCESSO CIVIL E O PROCESSO PENAL}


A atual perspectiva constitucional - publicista e contemporânea - do Direito Processual Civil faz com que se busque cada vez mais, seja no campo normativo ou jurisdicional, a efetivação dos princípios constitucionais relacionados ao sistema processual: contraditório, ampla defesa, publicidade, fundamentação, entre outros.

Fala-se aqui em perspectiva atual, mas sem perder de vista a busca histórica, que sempre pautou os estudos de parte da doutrina, por um Processo Civil mais democrático, a exemplo da construção teórica de "acesso à justiça" de Mauro Cappelletti e Bryant Garth. Tal democratização do Processo Civil, atrelada ao acesso à justiça, não destoa, evidentemente, da efetivação dos princípios constitucionais. (CAPPELLETTI; GARTH, 2002)

É fato incontestável que estes princípios são comuns ao Processo Penal, com redobrada importância, vez que nesta área se constituem como instrumentos essenciais à limitação do poder punitivo estatal.

Salienta-se, portanto, a relevância dos princípios constitucionais (devido processo legal, contraditório, ampla defesa, etc.) no âmbito processual penal, enquanto verdadeiras garantias contra o arbítrio estatal. Segue-se aqui como base teórica a ideia de "garantismo" concebida por Luigi Ferrajoli. (FERRAJOLI, 2006)

Desta forma, é inconcebível admitir, num Estado Democrático de Direito, a existência de "processos" em que garantias sejam violadas. Pode-se dizer, inclusive, que há nítida relação entre respeito a princípios e qualidade da democracia. (FERRAJOLI, 2006)

Respeito à Constituição e, sobretudo, aos princípios e aos direitos fundamentais é o que se espera tanto no Processo Civil, quanto no Processo Penal.

Ocorre que, em determinados aspectos, a evolução do Processo Civil, rumo à estruturação de um sistema processual democrático e constitucional, tem sido mais rápida do que a do Processo Penal, de forma que parece extremamente adequado que estes

\footnotetext{
${ }^{1}$ Os autores trabalham com a ideia de que o acesso à justiça seria uma espécie de direito social básico e que a sua efetividade estaria relacionada com a "completa igualdade de armas". Contudo, reconhecem os autores que tal hipótese é utópica. Segundo eles "a questão é saber até onde avançar na direção do objetivo utópico e a que custo"'.

${ }^{2}$ Interessante consignar o conceito de garantismo intuído por Ferrajoli: "se habla así de garantismo patrimonial para designar el sistema de garantías que tutelan el derecho de propiedad y el resto de derechos patrimoniales; de garantismo liberal, y especificamente penal, para designar las técnicas establecidas para la defensa de los derechos de libertad, sobre todo la libertad personal, frente a intervenciones policiales o judiciales arbitrarias; de garantismo social para designar el conjunto de garantías, todavía bastante escasas e imperfectas, encaminadas a satisfacer los derechos sociales, como los derechos a la salud, a la educación, al trabajo, etcétera". (FERRAJOLI: 2006, p. 11)
} 
aprimoramentos, quando de natureza garantista e/ou constitucional, sejam recepcionados no âmbito da jurisdição processual penal.

É evidente, por sua vez, que normas processuais civis que eventualmente restrinjam direitos fundamentais ${ }^{3}$ não poderão ter aplicação ao Processo Penal.

Importante esclarecer que não se está aqui advogando em prol de uma pretensa teoria geral do processo, mas apenas defendendo-se o aproveitamento pela jurisdição penal de normas processuais civis que ampliam o espectro de garantias fundamentais, realidade comum no âmbito do Processo Civil contemporâneo.

Adequado é o posicionamento de Aury Lopes Jr no sentido de que o Processo Penal deve ter roupagem própria, distinta da conferida ao Processo Civil. O referido autor parte da metáfora da "Cinderela", criada por Carnelutti, para sustentar que o Processo Penal precisa ser pensado a partir de premissas próprias, não podendo ficar restrito ao uso "das roupas velhas de sua irmã".

Mas, em relação ao Direito Penal, a autonomia obtida é suficiente, até porque, como
define Carnelutti, delito e pena são como cara e coroa da mesma moeda. Como o são
Direito Penal e Processual Penal. Mas o problema maior está na relação com o
processo civil. O processo penal, como a Cinderela, sempre foi preterido, tendo de
se contentar em utilizar as roupas velhas de sua irmã. Mais do que vestimentas
usadas, eram vestes produzidas para sua irmã (não para ela). A irmã favorita aqui,
corporificada pelo processo civil, tem uma superioridade científica e dogmática
inegável. (LOPES JR, 2015)

Contudo, inobstante a ressalva inicial, é possível depreender da construção teórica do referido autor que diversos institutos do Processo Civil dialogam com o Processo Penal. Este diálogo entre institutos, sobretudo relacionados à nova estruturação democrática do Processo Civil, vem sendo ressaltada por parcela da doutrina.

Neste sentido é o posicionamento de Sérgio Freitas e Maria Fernanda Sales, os quais sustentam que a nova legislação processual civil trouxe "relevantes repercussões no âmbito processual penal, em razão de sua aplicação supletiva e subsidiária”. (FREITAS; SALES, 2016, p. 557)

\footnotetext{
${ }^{3}$ Não se pode perder de vista determinados perigos relacionados ao uso de "princípios" criados discursivamente para justificar limitações a direitos fundamentais, em nome de pretensos interesses coletivos. São os perigos daquilo que Lenio Streck nomina como "pan-pricipiologismo". O referido autor afirma inclusive que existe uma "bolha especulativa dos princípios, espécie de subprime do direito". Desta forma não há que se admitir construções "pan-principiológicas" limitativas de direitos fundamentais. Posição crítica desenvolvida pelo autor manifestada em https://www.conjur.com.br/2012-mar-22/senso-incomum-pan-principiologismo-sorriso-lagarto
} 
Vale destacar, ainda a partir do pensamento dos referidos autores, que, inobstante as relevantes implicações das inovações processuais civis no Processo Penal, ainda "são rasos $e$ esparsos os escritos acerca da matéria", ou seja, há escassez doutrinária sobre o tema. (FREITAS; SALES, 2016, p. 557)

Desta forma, torna-se ainda mais justificada a realização de pesquisas voltadas à verificação da possibilidade de aplicação das novas normas do Processo Civil ao Direito Processual Penal.

Exemplo de possibilidade conectiva de institutos, conforme se propõe a título de hipótese no presente trabalho, é o que dispõe o atual Código de Processo Civil sobre a fundamentação das decisões judiciais. O conteúdo do art. 489 do referido Codex promoveu evidente reforço normativo ao princípio constitucional da fundamentação (art. 93, IX da $\mathrm{CF} / 88)$.

Outrossim, não se pode deixar de observar que tal reforço à fundamentação é também reforço ao próprio princípio do contraditório e ao caráter publicista do processo, ou seja, tratase, ao que parece, de ampliação em "cascata" de garantias fundamentais. (THEODORO JR, 2015)

Eis o ponto central: as alterações do Processo Civil adequadas dogmaticamente e ampliativas de garantias fundamentais podem ser aplicadas ao Processo Penal, de forma a se ampliar, igualmente, a dimensão democrática deste último.

Ademais, insta destacar que o Código de Processo Penal, por força do art. $3^{\circ}$, admite "interpretação extensiva e aplicação analógica, bem como o suplemento dos princípios gerais de direito". É claro que tal dispositivo deve receber interpretação constitucional e se adequar à tutela dos direitos fundamentais, exatamente o que se ressalta nos parágrafos anteriores da pesquisa aqui apresentada.

Sobre o art. $3^{\circ}$ do Código de Processo Penal, Renato Brasileiro de Lima sustenta que deve se ter cautela na aplicação do novo Código de Processo Civil para fins processuais penais, justamente porque tal possibilidade, no seu entender, tem natureza subsidiária. Não obstante a cautela sugerida, o autor reconhece a hipótese como válida. (LIMA, 2015)

Eugênio Pacelli, em nota à $20^{\mathrm{a}}$ edição do seu "Curso de Processo Penal, também afirma a possibilidade de aplicação analógica do novo Código de Processo Civil, destacando que entendimento diferente deste, sustentado na eventual impossibilidade de utilização na 
seara processual penal, "inviabilizaria até mesmo o manejo do Recurso Especial, o que seria, no mínimo, uma ofensa inaceitável à Constituição". (PACELLI, 2016)

Em linha similar, os autores Nestor Távora e Rosmar Rodriges Alencar abordam a existência de variados reflexos do novo Código de Processo Civil no Processo Penal, tais como a supressão das denominadas condições da ação e a regulamentação da cooperação jurídica internacional para fins probatórios. (ALENCAR; TÁVORA, 2016)

Anderson de Paiva Gabriel, por sua vez, destaca a aplicação da nova lei processual civil ao Direito Processual Penal, notadamente por estabelecer uma concepção constitucional de processo:

Nesse cenário, veio a lume o novo Código de Processo Civil (Lei no 13.105/2015), claramente norteado por uma concepção constitucional do processo, como não poderia deixar de ser, face a supremacia da CRFB/88. Se o diploma anterior, com todos os defeitos, já era aplicado supletiva e subsidiariamente ao processo penal, quiçá a novel lei. (GABRIEL, 2017, 02)

O que se propõe no presente artigo, partindo-se da mesma premissa elegida pelos autores citados, é justamente a aplicação do novo Código de Processo Civil ao Processo Penal sempre que se verificar o viés constitucionalista, refletido na ampliação de garantias processuais e de direitos fundamentais.

\section{A RELEVÂNCIA DA FUNDAMENTAÇÃo}

A fundamentação é componente essencial de um processo justo, conforme leciona Luiz Guilherme Marinoni. O autor sustenta que "sem motivação ${ }^{4}$ a decisão judicial perde duas características centrais: a justificação da norma jurisdicional para o caso concreto e a capacidade de orientação das condutas sociais”. (MARINONI, 2017, p. 516)

Ressaltando a importância do ato de decidir, Fredie Didier Jr sustenta que o juiz, ao sentenciar, cria uma norma jurídica individualizada, mas, diante de tal relevância ao atuar, "exige-se do juiz uma postura muito mais ativa, cumprindo-lhe compreender as

\footnotetext{
${ }^{4} \mathrm{O}$ autor utiliza o termo motivação. Mais à frente se verá que Humberto Theodoro Jr constrói raciocínio no sentido de que fundamentação e motivação não se confundem, já que a primeira seria muito mais ampla que a segunda. Não obstante, ao que tudo indica, Luiz Guilherme Marinoni confere à motivação conteúdo aproximativo daquele que Humberto Theodoro Jr entende por fundamentação.
}

Revista de Processo, Jurisdição e Efetividade da Justiça | e-ISSN: 2525-9814 | Salvador | v. 4 | n. 1 | p. 37 
particularidades do caso concreto e encontrar, na norma geral e abstrata, uma solução que esteja em conformidade com as disposições e princípios constitucionais". (DIDIER JR, 2012, p. 02)

A despeito desta importância, no campo do Direito Processual Penal, muito embora a fundamentação decisória tenha status de princípio constitucional e o art. 381 do Código de Processo Penal diga que a sentença deve conter "a indicação dos motivos de fato e de direito em que se fundar a decisão", nunca restou minimamente delimitado pela legislação vigente o que é necessário para se considerar uma fundamentação idônea e/ou adequada, atividade que fica a cargo dos 'bons' ou 'maus' ventos jurisdicionais, ocasionando inegável insegurança jurídica.

Ocorre que a falta de fundamentação é um problema gravíssimo, pois enfraquece a totalidade de garantias processuais. Mais uma vez nas palavras de Luiz Guilherme Marinoni: "sem contraditório e sem motivação adequados não há processo justo". (MARINONI, 2017, p. 517)

Dentro desta abertura normativa do Processo Penal, não é incomum a existência de decisão proferida ao arrepio do debate travado entre acusação e defesa, passando ao largo do contraditório; ou de decisão que ignora propositadamente a antítese defensiva e limita-se a apontar razões genéricas de convencimento.

Adriano Bretas sustenta que "a fundamentação genérica, os clichês e chavões, as fórmulas vazias, aplicáveis a qualquer caso, sem indicação empírica nos dados objetivos do caso concreto em julgamento, também maculam a sentença de tisna nulificante". A afirmação é de certa forma simples: de nada adiantam decisões que abstratamente podem servir para qualquer caso. (BRETAS, 2017, p. 220).

Tais decisões se mostram em descompasso com o princípio do contraditório, vez que este pressupõe o debate e a possibilidade de influência real dos argumentos das partes. Agora, "como é de facílima intuição, não é possível aferir" se a influência foi efetiva se não há dever judicial de rebate aos fundamentos levantados pelas partes". (MARINONI, 2017, p. 517)

Relevante colacionar o entendimento de Anderson de Paiva Gabriel no sentido de que o contraditório (participativo) é pressuposto de legitimação da decisão judicial:

\footnotetext{
${ }^{5}$ A questão proposta por Marinoni indica violação ao princípio do contraditório, enquanto garantia efetiva, pois é preciso que as partes saibam se aquilo que provaram ou argumentaram foi objeto de cognição pelo julgador, o que não se verifica por uma decisão vazia, lacônica ou genérica. A fundamentação é, portanto, instrumento de efetivação do contraditório.
}

Revista de Processo, Jurisdição e Efetividade da Justiça | e-ISSN: 2525-9814 | Salvador | v. 4 | n. 1 | p. 37 
Emerge dessa visão contextualizada a jurisdição contemporânea, prestada pelo processo justo, tendo por traço distintivo o contraditório participativo, por meio do qual os personagens do processo interagem, cooperam e dialogam, influenciando a convicção do julgador e permitindo a formação dialética da melhor decisão, ao mesmo tempo que a legitimam, tornando-a digna à luz do Estado democrático de direito. (GABRIEL, 2017, p. 13)

De forma extrema é possível sustentar que uma parte que não tem seus argumentos enfrentados desempenha papel tão irrelevante no processo quanto aquela que se queda inerte. Afinal, de que adianta expor inúmeras teses (constitutivas ou negativas; acusatórias ou defensivas) ao longo do processo, caso não haja obrigação do magistrado as analisar?

Ou ainda: de que adianta todo esforço no sentido de se produzir provas, com custo temporal e financeiro, se não houver referência a tais provas produzidas?

Estas dificuldades que continuam sendo enfrentadas (normativa e jurisdicionalmente) no Processo Penal também compunham a realidade normativa processual civil antes da edição do atual Código de Processo Civil, o qual, contudo, com base no $\S 1^{\circ}$ do art. 489, passou a estabelecer nítido instrumental contra decisões genéricas e distanciadas da análise detida do caso sob jurisdição. Salienta-se, desde já, que a mudança foi normativa, mas não necessariamente jurisdicional, sendo que algumas dificuldades já estão sendo "desenhadas" nos tribunais superiores.

Assim, relevante analisar, mais detidamente, as alterações da legislação processual civil, a partir da edição do novo Código, sobre a fundamentação das decisões judiciais, sobretudo para se visualizar o avanço na efetivação dos valores constitucionais.

\section{FUNDAMENTAÇÃO NO NOVO CÓDIGO DE PROCESSO CIVIL}

$\mathrm{O}$ art. 489, § $1^{\circ}$ do CPC/2015 estabelece mínimo normativo, dispondo sobre hipóteses que não podem ser tidas como fundamentação adequada, ou seja, a nova lei processual civil estabelece um tipo de regulamentação contrario sensu.

É relativamente simples: o dispositivo processual prevê o que não pode fazer o juiz (e não aquilo que ele deveria fazer). Desta forma, seguindo-se o atual Código de Processo Civil, 
o magistrado, em seu importante trabalho de fundamentação das decisões judiciais, não pode (ipsis litteris) ${ }^{6}$ :

(a) se limitar à indicação, à reprodução ou à paráfrase de ato normativo, sem explicar sua relação com a causa ou a questão decidida;

(b) empregar conceitos jurídicos indeterminados, sem explicar o motivo concreto de sua incidência no caso;

(c) invocar motivos que se prestariam a justificar qualquer outra decisão;

(d) não enfrentar todos os argumentos deduzidos no processo capazes de, em tese, infirmar a conclusão adotada pelo julgador;

(e) se limitar a invocar precedente ou enunciado de súmula, sem identificar seus fundamentos determinantes nem demonstrar que o caso sob julgamento se ajusta àqueles fundamentos;

(f) deixar de seguir enunciado de súmula, jurisprudência ou precedente invocado pela parte, sem demonstrar a existência de distinção no caso em julgamento ou a superação do entendimento.

De acordo com o que se extrai do referido dispositivo legal, revela-se perceptível a preocupação do legislador em evitar: decisões genéricas, desvinculadas do caso concreto e afastadas do contraditório.

Esta reflexão é de todo importante, pois a Constituição Federal efetivamente já estabelecia a necessidade de fundamentação das decisões judiciais no art. 93, IX. Contudo, a tergiversação retórica relacionada ao princípio da fundamentação - quase desnaturando o conteúdo normativo constitucional - torna necessária a tomada de medidas legislativas como essa inscrita no bojo do novo Código de Processo Civil.

De acordo com Marcelo Mazzola a alteração na forma de decidir é positiva e evita decisões marcadas por graves falhas técnicas, a exemplo das "decisões lacônicas ('Diante da presença dos elementos autorizadores da medida, defiro') ou embasadas em conceitos jurídicos vagos ('Em nome da ordem pública e da dignidade da pessoa humana, defiro a tutela')", bem como das decisões genéricas, aquelas que servem para qualquer caso, mas não descem às minúcias do caso concreto. (MAZZOLA, 2016)

\footnotetext{
${ }^{6}$ É interessante observar que o Novo Código de Processo Civil não instituiu positivamente requisitos detalhados de uma fundamentação adequada, ao contrário, o legislador trabalhou pela perspectiva negativa, estabelecendo proibições ao magistrado, ou seja, dizendo aquilo que não é fundamentação adequada.
} 
É imperioso concordar com Humberto Theodoro Jr na afirmação de que "não podemos mais tolerar as simulações de fundamentação nas quais o juiz repete o texto normativo ou a ementa de julgado que lhe pareceu adequado ou preferivel, sem justificar a escolha". Relevante é que as decisões passem a ser proferidas de forma realmente fundamentadas, vez que a fundamentação decisória é garantia limitativa do arbítrio e da discricionariedade. (THEODORO JR, 2015, p. 219)

Os limites da fundamentação decisória servem, também, à evitação de decisões surpresas, desconectadas do contraditório e da ampla defesa:

\begin{abstract}
Esta prohibición consiste en la imposibilidad de juzgar o pronunciarse sobre una cuestión o punto respecto del cual las partes no se han manifestado previamente, incluso - y ahí está la novedad legislativa implementada por el Código Procesal Civil brasileño de 2015 (en adelante, CPC) - en relación con las materias conocidas de oficio por el juzgador. Es en ese sentido que el tema aquí comentado está conectado con el principio constitucional de contradicción y amplia defensa. En efecto, este, como principio, ofrece un aspecto de universalidad y generalidad, lo que propicia una rica concepción comparatista, incluso independientemente de la existencia de una norma procesal específica que contemple de forma expresa la prohibición de la decisión sorpresa, toda vez que esta es una dimensión del principio de contradicción y amplia defensa. (ZUFELATO, 2017)
\end{abstract}

Portanto, conforme já se afirmou de início, é nítido que o novo Código ampliou o conteúdo do princípio da fundamentação - embora existentes críticas sobre abertura de determinados incisos - dando nova dimensão a esta garantia constitucional, o que torna plenamente viável a aplicação dos dispositivos legais referidos no âmbito da jurisdição processual penal.

Isto porque, por seu viés garantista, deve o Processo Penal exigir decisões minuciosamente fundamentadas, como forma de se verificar o respeito ao contraditório e elevar a percepção democrática da ampla defesa.

É evidente que sempre existe o risco de que o dispositivo ampliativo do princípio da fundamentação (art. 489 do CPC/2015) acabe "ganhando" restrições desenhadas jurisdicionalmente, no próprio âmbito processual civil, conforme se extrai de posicionamento "atual" do Superior Tribunal de Justiça. Assim, de partida já se tem esta dificuldade, pois, caso haja limitação à aplicação no Processo Civil, quem dirá no Processo Penal, o qual estará fazendo "uso" da norma em caráter supletivo.

Vale ressaltar, sobre esta preocupação, que não se trata de crítica apriorística ou de mera suposição, mas de receio oriundo de decisão proferida pelo Superior Tribunal de Justiça após a vigência do novo Código de Processo Civil. 
Analisando decisão do STJ, proferida no EDcl no $M S$ 21.315/DF, Rodrigo Becker e Victor Trigueiro apontam que o referido tribunal superior contrariou a essência da norma (art.489) ao decidir - em resumo - que "o julgador não está obrigado a responder a todas as questões suscitadas pelas partes, quando já tenha encontrado motivo suficiente para proferir a decisão". (BECKER; TRIGUEIRO, 2016)

Os autores citados transcreveram fragmento da ementa, o qual aqui se colaciona para a finalidade de ilustrar o posicionamento do STJ:

O julgador não está obrigado a responder a todas as questões suscitadas pelas
partes, quando já tenha encontrado motivo suficiente para proferir a decisão. A
prescrição trazida pelo art. 489 do CPC/2015 veio confirmar a jurisprudência já
sedimentada pelo Colendo Superior Tribunal de Justiça, sendo dever do julgador
apenas enfrentar as questões capazes de infirmar a conclusão adotada na decisão
recorrida. (STJ: EDcl no $M S$ S 21.315/DF)

A impressão que fica é a de que o STJ está repetindo entendimento anterior ao novo Código, firmado pelo Supremo Tribunal Federal, no sentido de que o juiz não está obrigado a analisar todas as alegações das partes, sem se atentar para a relevância das mudanças de efetivação da Constituição.

Discordando deste entendimento, Humberto Theodoro Jr sustenta que o STF (e por consequência também o STJ) confunde fundamentação com motivação, posição que não se coaduna com as novas escolhas legislativas, já que a motivação enseja um ato de criação solitária e solipsista, forma de atuar que choca com a nova dimensão colaborativa e publicita do direito processual civil. (THEODORO JR, 2015, p. 222)

É imperioso concordar com o mencionado autor, pois a decisão proferida pelo Superior Tribunal de Justiça, revivendo a jurisprudência anterior ao novo Código, acaba por contrariar as modernas tendências processuais civis, além de inobservar deliberadamente o conteúdo legislativo dado à fundamentação das decisões judiciais. É como se nada tivesse mudado com a vigência do CPC/2015.

Contudo, inobstante o registro da preocupação com os caminhos jurisdicionais sobre o princípio da fundamentação, não se pode perder de vista a relevante transformação operada legislativamente, a fim de, finalmente, buscar se estabelecer a conexão - possível - com o Direito Processual Penal. 


\title{
4. APLICAÇÃO DAS NOVAS REGRAS AO PROCESSO PENAL
}

Enfim, muito embora verifique-se incerteza jurisdicional nos novos rumos construtivos de uma teoria da decisão, a partir do CPC de 2015, ao menos normativamente, o que se tem é a certeza de que o Direito Processual Civil ampliou os requisitos para a fundamentação das decisões judiciais. Esta expansão da cláusula constitucional resta evidenciada nas palavras de Humberto Theodoro Jr:

\begin{abstract}
Ao se partir dessa percepção e ao analisar o modo como as decisões são fundamentadas, torna-se imperativa uma nova perspectiva dinâmica (substancial) para a referida cláusula constitucional, também com o respaldo de uma legislação que promova a expansividade e perfectibilidade típicas do modelo constitucional de processo brasileiro, ou seja, aplicação concreta da garantia e que expanda o próprio conteúdo do texto da Constituição. (THEODORO JR, 2015, p. 220)
\end{abstract}

Assim, a aplicação dos novos "requisitos" de fundamentação não é só possível, mas sim necessária no âmbito processual penal. Nesta linha de compreensão, Fernando Fonseca Gajardoni pondera que as novas regras ao menos devem ter efeito pedagógico no Processo Penal. (GAJARDONI, 2015)

Contudo, é de se acreditar que tal efeito pedagógico não basta. É preciso ir além, sendo indispensável a problematização das decisões proferidas no âmbito processual penal de acordo com as novas regras do Direito Processual Civil, observando-se, por evidente, as compatibilidades dogmáticas e adequações estruturais.

Convém destacar aqui a reflexão de Anderson de Paiva Gabriel sobre a inserção de normas fundamentais no novo Código de Processo Civil de forma a balizar "um modelo constitucional de processo alinhado ao Estado democrático de direito". Em razão desta democratização, o autor sustenta ser imperiosa a aplicação destas normas fundamentais ao processo penal, “acarretando o diálogo entre as fontes processuais". (GABRIEL, 2017, p. 04)

É o que se sustenta aqui: as normas processuais civis que seguem modelo ampliativo constitucional devem ser aplicadas ao Processo Penal, notadamente as regras que delineiam, de forma garantista, uma nova moldura de fundamentação decisória

Afinal, não é minimamente razoável que um mesmo tribunal siga dois métodos decisórios, um mais fundamentado (processo civil) e um menos fundamentado (processo 
penal), como se os valores discutidos fossem de menor importância no segundo caso, premissa absolutamente falsa.

Muito embora os conteúdos avaliados em decisões cíveis e penais sejam distintos, bem como possam obedecer a rigores constitucionais mais ou menos amplos, não se pode desconsiderar a existência de pontos comuns, de forma a ser possível afirmar que decisões judiciais (cíveis ou penais) possuem determinados padrões, os quais podem ser objeto de cognição científica, inclusive a partir de bases teóricas exógenas ao próprio Direito. A fim de ilustrar este raciocínio, relevante colacionar a lição de Cláudia Servilha Monteiro:

Os fundamentos da Teoria da Decisão no Direito são constituídos por três ordens de
postulados teóricos. Da Metamatemática emanam as formulações da Teoria da
Decisão, da Filosofia provêm as premissas sobre formação do raciocínio e dos seus
modelos de racionalidade e do próprio Direito procedem as elucidações de conceitos
da Hermenêutica Jurídica, da Teoria da Argumentação Jurídica e da Teoria
Dogmática da Aplicação do Direito. Assim, a Teoria da Decisão Judicial é produto
de algumas hibridaçôes disciplinares que constituem como uma interdisciplina eem
que hipóteses colam conceitos estratégicos da Teoria da Decisão da Metamatemática
a outros filosóficos, jusfilosóficos e teórico-jurídicos. (MONTEIRO, 2017, p. 6106)

Assim, o processo decisório deve ter um lugar comum, certo rigor metodológico e observar certos padrões universalizantes, dados por elementos legais ou jurisdicionais. A exigência de fundamentação decisória é um destes padrões comuns, pois a Constituição, ao estabelecer a exigência "fundamentadora" (art.93,IX), não a restringe a uma ou outra área do Direito. Agora, se o desdobramento conceitual (ampliativo) definidor do que vem a ser fundamentação é dado apenas pelo Processo Civil, silenciando o Processo Penal, a extensão de incidência é plenamente justificada, pois o ato de fundamentar é componente indissociável do ato de decidir, a partir de perspectiva comum estruturadora de uma teoria da decisão.

De acordo com Matheus Sasseron e Rodrigo Ribeiro a motivação - tão importante no âmbito civil, onde, via de regra, se discutem direitos disponíveis - tem destaque ainda maior no âmbito penal, em que se coloca em "posição antagônica Estado e indivíduo, em patente posição de (natural) desigualdade, com o gravame de estar em jogo o mais caro bem jurídico; a liberdade". (SASSERON; RIBEIRO, p. 2015)

Enfim, é evidente que as decisões proferidas no âmbito processual penal devem ser adequadamente fundamentadas, sob pena de se violar o art. 93, IX da Constituição Federal.

Desta forma, considerando-se, de um lado, a construção jurisprudencial restritiva do conteúdo do princípio e, de outro lado, a ampliação conceitual de destaque ao princípio realizada pelo novo Código de Processo Civil, chega-se à constatação de que aplicar o art. 489 
do CPC/2015 no Processo Penal é medida que está de acordo com a Constituição e com os princípios processuais, revelando-se, portanto, não apenas ser possível tal hipótese, mas necessária.

\section{CONSIDERAÇÕES FINAIS}

A partir do desenvolvimento do presente trabalho de pesquisa, tendo como ponto de partida o problema da aplicabilidade das novas normas processuais civis, sobre fundamentação decisória, ao Processo Penal, é possível chegar às seguintes conclusões:

A uma, de forma geral é possível dizer que algumas normas processuais civis podem ser aplicadas ao Processo Penal. Em destaque: as alterações do Processo Civil adequadas dogmaticamente e ampliativas de garantias fundamentais podem ser aplicadas ao Processo Penal, de forma a se ampliar, igualmente, a dimensão democrática deste último. Em sentido contrário: normas processuais civis restritivas de direitos fundamentais não podem ter aplicabilidade processual penal.

A duas, a fundamentação das decisões judiciais, estabelecida como princípio constitucional, é elemento essencial à existência de um processo justo, conforme sustentam diversos autores, não podendo ser inadequada, seja no âmbito processual civil ou processual penal.

A três, o novo Código de Processo Civil parece ter buscado a efetivação de valores constitucionais e publicitas, seguindo as teorias - contemporâneas e democráticas processuais desenvolvidas nas últimas décadas, tendo se preocupado com o reforço normativo de determinados princípios constitucionais. Tal reforço é evidente em variados artigos da nova legislação processual.

A quatro, o novo Codex ampliou o conteúdo do princípio da fundamentação decisória, dando nova dimensão (ampliativa) a esta garantia constitucional, a partir de regulamentação, contrario sensu, estabelecida no seu art. 489. O dispositivo nitidamente se preocupou com a evitação de decisões genéricas, lacônicas e divorciadas das peculiaridades do caso concreto debatido em contraditório. 
A cinco, levando-se em conta a ampliação conceitual de destaque ao princípio da fundamentação, realizada pelo novo Código de Processo Civil, chega-se à constatação de que aplicar o art. 489 do CPC/2015 ao Processo Penal é medida que está de acordo com a Constituição e com os princípios processuais, revelando-se, portanto, não apenas ser possível, mas necessária.

Assim sendo, sustenta-se por fim que as normas processuais civis, que dispõem sobre a fundamentação decisória, devem ser observadas nas decisões proferidas no campo jurisdicional penal.

\section{REFERÊNCIAS}

ALENCAR, Rosmar Rodrigues; TÁVORA, Nestor. Curso de direito processual penal. 11 ed. Editora JusPODIVM, 2016.

BRETAS, Adriano Sérgio Nunes. Apontamentos de processo penal. Curitiba: Sala de Aula Criminal, 2017.

CAPPELLETTI, Mauro; GARTH, Bryant. Acesso à justiça. Tradução de Ellen Gracie Northfleet. Porto Alegre: Sergio Antônio Fabirs Editor, 2002.

DIDIER JR, Fredie. Sobre a fundamentação da decisão judicial. Fredie Didier, 2012. Acesso em 07.12.2017. Disponível no link: http://www.frediedidier.com.br/wp-content/uploads/ 2012/02/ sobre-a-fundamentacao-da-decisao-judicial.pdf

FREITAS, Sérgio Henrique Zandona; SALES, Maria Fernanda de Souza. O processo penal brasileiro e os impactos provenientes do novo código de processo civil. Revista Direito Penal, Processo Penal e Constituição. ISSN: 2526 -0200. Brasília, v. 2, n. 1, p. 5, Jan/Jun. 2016.

FERRAJOLI, Luigi. Garantismo penal - série: estudios jurídicos 34. Universidad Nacional Autónoma de México, 2006.

GABRIEL, Anderson de Paiva. O contraditório participativo no processo penal: uma análise da fase pré-processual à luz do código de processo civil de 2015 e da constituição. 1. ed. Rio de Janeiro: Gramma, 2017.

GAJARDONI, Fernando da Fonseca. Coleção repercussões do novo CPC: magistratura. Salvador: JusPODIVIM, 2015.

LIMA, Renato Brasileiro de. Manual de processo penal. 3 ed. Salvador: Editora JusPODIVM, 2015. 
LOPES JR., Aury. Quando Cinderela terá suas próprias roupas? A necessária recusa à teoria geral do processo. Revista Brasileira de Direito Processual Penal, Porto Alegre, vol. 1, n. 1, p. 230-237, 2015. http://dx.doi.org/10.22197/rbdpp.v1i1.13

MARINONI, Luiz Guilherme. et.all. Novo curso de processo civil: teoria do processo civil volume 1. 3. ed. rev. atual. e ampl. São Paulo: Editora Revista dos Tribunais, 2017.

MAZZOLA, Marcelo. O dever de fundamentação no novo CPC. Jota Info, 2016. Acesso em 03.12.2017. Disponível no link: https://jota.info/artigos/o-dever-de-fundamentacao-no-novocpc-08012016

MONTEIRO, Fundamentos para uma teoria da decisão judicial. Manaus: Conpedi. Acesso em 03.12.2017. Disponível em http://www.publicadireito.com.br/conpedi/manaus/arquivos/ anais/bh/claudia_servilha_monteiro.pdf

PACELLI, Eugênio. Curso de processo penal. 20. ed. São Paulo: Atlas, 2016.

RUBIN, Fernando. Fragmentos de processo civil moderno: de acordo com o novo CPC. Porto Alegre: Livraria do Advogado Editora, 2013.

SASSERON, Matheus Henrique; RIBEIRO, Rodrigo Muterle. Da aplicação da sistemática do art. $489, \S 1^{\circ}$ do novo CPC às decisões proferidas em âmbito penal. Jusbrasil, 2015. Acesso em 10.12.2017. Disponível no link: https://matheussasseron.jusbrasil.com.br/artigos/305037683/ da-aplicacao-da-sistematicado-art-489-1-do-novo-cpc-as-decisoes-proferidas-em-ambito-penal

SILVARES, Ricardo; PINTO, Ronaldo Batista. Novo CPC e seus reflexos no âmbito do processo penal. Salvador: Editora JusPODIVM, 2016.

THEODORO JR, Humberto. et. all. Novo CPC - fundamentos e sistematização. Rio de Janeiro: Forense, 2015.

TRIGUEIRO, Victor; BECKER, Rodrigo. O STJ e a fundamentação das decisões. Jota Info, 2016. Acesso em 03.12.2017. Disponível no link: https://jota.info/colunas/coluna-cpc-nostribunais/cpc-nos-tribunais-o-stj-e-fundamentacao-das-decisoes-29092016

ZUFELATO, Camilo. La dimensión de la «prohibición de la decisión-sorpresa» a partir del principio de contradicción en la experiencia brasileña y el nuevo Código Procesal Civil de 2015: reflexiones de cara al derecho peruano. Lima, n. 78, p. 21-42, enero 2017 - $\quad$ Disponible en <http://www.scielo.org.pe/scielo.php?script=sci_arttext\&pid=S025134202017000100002\&ln $\mathrm{g}=\mathrm{es} \& \mathrm{nrm}=\mathrm{iso}>$. Acedido en 06 abr. 2018. 